\title{
A mathematical model for optimal tower crane layout planning
}

\author{
Mojtaba Hosseini ${ }^{a^{*}}$, Peyman Beiranvand ${ }^{\mathrm{b}}$, Mohammad Reza Dadgar ${ }^{\mathrm{c}}$ and Amin Olfati $^{\mathrm{d}}$
}

${ }^{a}$ Associate Professor, Department of Civil Engineering, Lorestan University, Khorram abad, Iran

${ }^{b} \mathrm{PhD}$ Candidate, Department of Civil Engineering, Razi University, Kermanshah, Iran

${ }^{c}$ M.SC, Department of Civil Engineering, Islamic Azad University, Abhar, Iran

${ }^{d}$ Sama Technical and Vocational Training College, Islamic Azad University, Khorramabad Branch, Khorramabad, Iran

\section{H R O N I C L E}

\begin{tabular}{l}
\hline Article history: \\
Received October 3,2016 \\
Received in revised format: \\
October 22, 2016 \\
Accepted February 8,2017 \\
Available online \\
February 82017 \\
\hline Keywords: \\
Tower crane \\
Location \\
Operating time \\
Feasible area \\
\hline
\end{tabular}

\section{A B S T R A C T}

\begin{abstract}
Tower cranes, on today's typical building construction sites, are the centerpiece of production, hoisting and transporting of a variety of loads. Due to a simple crane limited capacity; there is an urgent need to use high capacity cranes such as tower cranes. However, we have to select an appropriate type of cranes to be utilized to reduce the associated coste as much as possible. In this research, we propose a method to select the suitable type of crane and locate the best place for crane erection based on a minimum radius for requested crane and minimum cost. To fulfill the target, a computer program is designed to numerate these problems, demonstrating an example explaining how to apply the program and the results are discussed.
\end{abstract}

(C) 2017 Growing Science Ltd. All rights reserved.

\section{Introduction}

During the past few years, there have been tremendous attempts for locating a crane with mimmum time for crane movements, which leads to cost miminization (Xiaoyi et al., 2009; Herrera \& Kaczmarczyk, 2016). Warszawski (1973) proposed a time distance formula in which quantitative evaluation of location was possible. Furusaka and Gray (1984) presented a dynamic programming model with the objective function being hire cost, but without consideration of location. Gray and Little (1985) optimized crane location in irregular-shaped building while Wijesundera and Harris (1986) designed a simulation model to reconstruct operation times and equipment cycles when handling concrete. Farrel and Hover (1989) developed a database with a graphical interface to assist crane selection and location. Choi and Harris (1991) introduced another model to optimize single tower crane location by calculating total transportation times incurred. Wu et al. (2010) developed an algorithm for locating mobile cranes on construction sites, by considering the lifting capacity, the geometrical characteristics of the crane, the dimensions of equipments and riggings, and the ground bearing * Corresponding author. Tel: +98 9163973584

E-mail address: Hosseini.m@lu.ac.ir (M. Hosseini) 
pressure. Theie proposed method was incorporated into a three-dimensional (3D) computer-aided system, which includes crane modeling module, crane selection module, 3D-simulation module, 3D computer-aided design modeling module, rigging calculation module, and data management module. Olearczyk et al. (2014) proposed a method for the crane selection process and introduced mathematical methods to evaluate the construction of multi-lift operations. The modular lift process in this study was divided into three stages: crane load and capacity check, crane location, and boom and superlift clearance. Each stage's parameters were introduced, analyzed, and graphically explained. The methodology logic was supported by a generalized mathematical algorithm and was implemented and examined on a case study involving the construction of five three-storey dormitories in 10 working days for Muhlenberg College in Allentown, Pennsylvania. Tubaileh (2016) presented a technique for optimizing the layout of single tower crane and supply material locations. The crane is considered as a robot with multi degrees-of-freedom and the displacement of each joint was stated as a cubic spline. He proposed a model to build working time optimized crane operations. Both kinematics and dynamic models were considered to describe the crane motion necessities. The constraints imposed on crane velocity, acceleration, jerk and power were also taken into account to provide efficient planning and scheduling of crane operations, as well as improving the general performance and safety characteristics of the crane.

In this research, we present a methematicl model to find minimum crane radius or getting feasible area, used to select the best location to erect crane. The crane location fulfills the minimum total time for all crane movements. We also present a numerical example to determine the proceeding crane radius, feasible area, and optimum location to erect crane.

\section{Model description}

Three steps are involved in determining the optimal position for a single crane: (a) selection of minimum radius, (b) feasible area of crane, and (c) optimization model applied to each position of crane in turn to find an exact optimal location of crane.

\subsection{Assumptions}

(a) Geometric layout of all supply and demand, $D$, locations, together with the type is predetermined.

(b) For each S-D pair, demand levels for transportation are known, e.g., total number of Lifts maximum load, unloading delay, etc.

(c) The duration of construction is broadly similar over the working area.

(d) Radius of crane is similar over the tasks.

(e) The area of each supplied location is large enough to include the storage necessities.

(f) The feasible locations for the supply locations are limited by the site conditions and shape of the permanent building.

\subsection{Methodology}

The suitable type of tower crane is the one which join all demand and supply locations including preparation workshop, storing space, maintenance workshop, fuel station and left over space. This is performed by drawing the coverage area of crane jib. In case that the site of work becames too large, storing materials and equipment may be sited outside load circles a head of time, which is not needed. When such materials and equipment are needed for utilization, it shall move inside the coverage area (carne transportation circles). 


\section{Analysis}

\subsection{Hook travel for performing task}

If $\left(\mathrm{XS}_{\mathrm{j}}, \mathrm{YS}_{\mathrm{j}}, \mathrm{ZS}_{\mathrm{j}}\right),\left(\mathrm{XD}_{\mathrm{j}}, \mathrm{YD}_{\mathrm{j}}, \mathrm{ZD}_{\mathrm{j}}\right)$ refer respectively, to the location of supply and demand task, for a crane located at $(\mathrm{X}, \mathrm{Y})$, the duration of hook travel, $T$, can be determined by the following equation.

$$
\mathrm{T}=\max \left(\mathrm{T}_{\mathrm{h}}, \mathrm{T}_{\mathrm{v}}\right)+\beta \min \left(\mathrm{T}_{\mathrm{h}}, \mathrm{T}_{\mathrm{v}}\right) .
$$

The duration of hook transportation time, $\mathrm{T}_{\mathrm{r}}$, is also calculated by the next equation.

$$
\mathrm{T}_{\mathrm{r}}=\mathrm{T}(\mathrm{Dj}, \mathrm{Sj})-\mathrm{T}(\mathrm{Sj}, \mathrm{Dj})+\mathrm{Nj}[\mathrm{L}(\mathrm{Sj})+\mathrm{T}(\mathrm{Sj}, \mathrm{Dj})+\mathrm{U}(\mathrm{Dj})+\mathrm{T}(\mathrm{Dj}, \mathrm{Sj})]
$$

where $T(D j, S j)$ is the travel time of unloaded hook from demand location, $D$, of task $j$ ' (produced by last request) to supply location, $S$, of the current request $j$.

$T(S j, D j) \quad$ is the hook travel time with loads form supply location, $S j$, to demand location, $D j$,

$T(D j, S j)$ is the hook travel time without loads from $D j$ to $S j$,

$L(S j) \quad$ is the hook delay time for loading at supply location $S j$, and

$U(D j) \quad$ is the hook delay time for unloading at $D j$.

$\mathrm{N}_{\mathrm{j}}=\frac{\mathrm{QR}}{\mathrm{C}}$

$\mathrm{Nj}$ is the number of lifting loads of crane which is to be calculated,

$Q$ is the total quantity of material transport between supply and demand locations,

$R$ is the radius of crane $\mathrm{jib}$, and

$C$ is the load capacity of tower crane.

Repetition is considered an essential factor in defining total time of lifting through this relationship. In addition, total cost, $T C$, can be calculated by the following formula.

$$
\mathrm{TC}=\sum \mathrm{TR}_{\mathrm{C}} \mathrm{C}_{\mathrm{j}}
$$

where, $C_{j}$ is the cost of material flow from supply location $S_{j}$ to demand location $D_{j}$ per unit quantity at each unit time. The required duration (time) for hook vertical and horizontal travel can be calculated by the following equations, accordingly.

$$
\begin{aligned}
& \mathrm{T}_{\mathrm{v}}=\frac{\left|\mathrm{Z}_{\mathrm{i}}-\mathrm{Z}_{\mathrm{j}}\right|}{\mathrm{V}_{\mathrm{v}}}, \\
& \mathrm{T}_{\mathrm{h}}=\operatorname{Max}\left(\mathrm{T}_{\mathrm{a}}, \mathrm{T}_{\mathrm{w}}\right)+\alpha \operatorname{Min}\left(\mathrm{T}_{\mathrm{a}}, \mathrm{T}_{\mathrm{w}}\right)
\end{aligned}
$$

where $T_{a}$ is the required duration for trolley radial movement and $T_{w}$ is the required duration for trolley tangent movement, being calculated from Fig. 1.

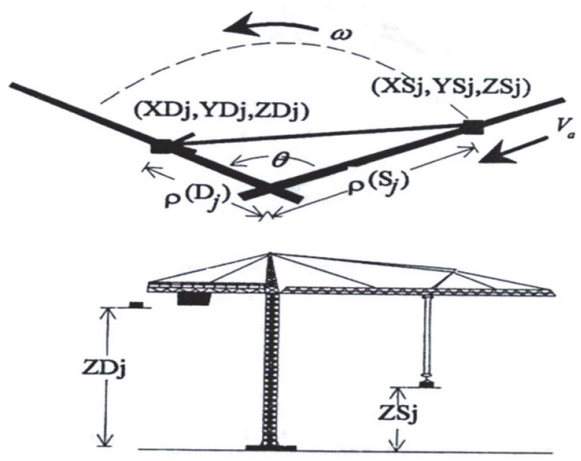

Fig. 1. Hook travel time 


$$
\begin{aligned}
& r\left(D_{J}\right)=\sqrt{\left(X_{J}-X\right)^{2}+\left(Y D_{J}-Y\right)^{2}} \\
& r\left(S_{J}\right)=\sqrt{\left(X S_{J}-X\right)^{2}+\left(Y S_{J}-Y\right)^{2}} \\
& L_{J}=\sqrt{\left(X_{J}-X_{J}\right)^{2}+\left(Y_{J}-Y S_{J}\right)^{2}}
\end{aligned}
$$

\subsection{Time for trolley radial movement}

$$
\begin{aligned}
& \mathrm{T}_{\mathrm{a}}=\frac{\left|\mathrm{r}\left(\mathrm{D}_{\mathrm{J}}\right)-\mathrm{r}\left(\mathrm{S}_{\mathrm{J}}\right)\right|}{\mathrm{V}_{\mathrm{a}}} \\
& \mathrm{T}_{\omega}=\frac{1}{\omega} \operatorname{Arc} \operatorname{Cos}\left(\frac{\mathrm{L}_{\mathrm{J}}{ }^{2}-\rho\left(\mathrm{S}_{\mathrm{J}}\right)^{2}-\rho\left(\mathrm{D}_{\mathrm{J}}\right)^{2}}{2 \rho\left(\mathrm{S}_{\mathrm{J}}\right) \rho\left(\mathrm{D}_{\mathrm{J}}\right)}\right)
\end{aligned}
$$

where $V_{a}$ is the radial velocity of trolley $(\mathrm{m} / \mathrm{min}), \omega$ is the slewing velocity of $\mathrm{jib}(\mathrm{r} / \mathrm{min})$, and $V_{v}$ is the hoist velocity of hook $(\mathrm{m} / \mathrm{min})$. Here, $\alpha$ and $\beta$ are two parameters between zero to one. $\alpha$ represents, the degree of coordination of hook movement in radial and tangential directions in the horizontal plan and $\beta$ reflects those in the vertical and horizontal planes. There are two extreme situations for $\alpha$. Simulations movement occurs when $\alpha=0$ and consecutive when $\alpha=1$, depending on the skill of the operator and the spaciousness of the site. For $\beta$ there are also two extreme situations: (a) simultaneous movement in two planes when $\beta=0$ (b) consecutive movements when $\beta=1$. The value of $\beta$ depends on the height of the working floor (the higher the floor the greater is $\beta$ ) ideally the value of both parameters need to be calibrated by observed date obtained from real construction sites. Kogane 1976 mentioned that an experienced driver performs simultaneous operations during $76 \%$ of the total duration of the cycle, thus here the value of parameter $\alpha$ is assumed as 0.25 unless otherwise stated, and $\beta$ is assumed as 1.0, i.e., the hook moves consecutively in two planes.

\subsection{Selection of minimum radius}

In this model, the beginning of design location of demand and supply is known then we select any small radius and determine the intersection between demand and supply, we calculate the length between all circles which represent the supply and the demand locations by Eq. (11) as follows,

$$
L=\sqrt{\left(X_{s}-X_{d}\right)^{2}+\left(Y_{s}-Y_{d}\right)^{2}}
$$

where:

$L:$ is the distance between all demand and supply locations,

$X_{s}$ and $Y_{s}$ : are the coordinates of supply locations,

$X_{d}$ and $Y_{d}$ : are the coordinates of demand locations.

The minimum length of crane jib should be equal to the maximum distance between all demand and supply locations.

$$
\mathrm{R}_{\min }=\frac{\mathrm{L}_{\max }+1}{2} \text {, }
$$

where:

$R_{\min }$ is the minimum radius of crane, and

$L_{\max }$ is the maximum distance between demand and supply locations. 
We repeat this process for single time or several times untill it gets the desired intersection which will be the minimum radius between the circles. For this reason, a computer program is written. By means of radius type and capacity and specification, the capability of crane requested can be selected. The steps of proposed algorithm will be summarized in the following steps.

(a) Coordinate of supply and demand locations are given.

(b) Calculate the length between all circles which represent the supply and the demand locations.

(c) Select maximum length from previous step.

(d) Minimum radius $=($ maximum length $/ 2)+0.50 \mathrm{~m}$.

\subsection{Feasible area}

Crane lift capacity is determined from the load-radius diagram in previous chapter where the greater the load, the smaller the crane is operating radius assuming a load at supply $(S)$ with the weight, its corresponding crane radius is $R$. A crane is therefore unable to lift a load unless it is located with a circle with the radius $R$. To deliver a load from $(S)$ to demand location (D), the crane has to be positioned within an elliptical area enclosed by two circles, shown in Fig. 2. The size of the area is related to the distance between $S_{i}$ and $D_{j}$. The large the weight of the load and the crane capacity of larger feasible area, the more easily the task can be handled. Due to the intersection of demand and supply circles, it could determine locations of intersections by solving the equation of two circles:

$$
\begin{aligned}
& \left(X-X_{s 1}\right)^{2}+\left(Y-Y_{s 1}\right)^{2}=R^{2} \\
& \left(X-X d_{2}\right)^{2}+\left(Y-Y_{d 2}\right)^{2}=R^{2}
\end{aligned}
$$

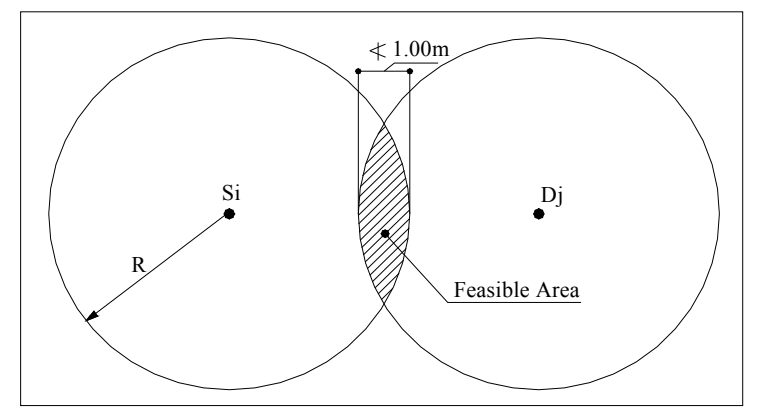

Fig. 2. Specified feasible area to locate the crane (Irizarry \& Karan, 2012)

where:

$X_{s 1}, Y_{s 1} \quad$ is the coordinate of supply location,

$X_{d 2}, Y_{d 2} \quad$ is the coordinate of demand location.

By solving the two Eqs. $(13,14) R$ is the radius of tower crane, which is calculated.

To determine locations of intersections, then we find locations not exceeding radius of crane (R) from all the previous circles.

$$
\mathrm{D}=\sqrt{\left(\mathrm{X}_{2}-\mathrm{X}_{1}\right)^{2}+\left(\mathrm{Y}_{2}-\mathrm{Y}_{1}\right)^{2}}
$$

where:

$D$ is the distance between all the previous locations and supply locations, demand locations, and 
$\left(\mathrm{X}_{1}, \mathrm{Y}_{1}\right)$ and $\left(\mathrm{X}_{2}, \mathrm{Y}_{2}\right)$ are the coordinates of two location on a line in feasible area. It is note that vertical distance between demand and supply locations.

As shown in Fig. 3, the feasible area of crane is determined by group of lines which connected by this mouthed the area between arc and lines in consider out of feasible area this assumption will be evaluate lately.

$$
\frac{\left(Y_{2}-Y_{1}\right)}{\left(X_{2}-X_{1}\right)}=\frac{\left(Y-Y_{1}\right)}{\left(X-X_{1}\right)}
$$

Fig. 4 shows available crane locations inside the feasible area which is determined by straight lines, it should be noted that Xmax, Xmin, Ymax, Ymin are determined. From the pervious step the net feasible area (which constrained by Xmax, Xmin, Ymax and Ymin) are divided by square mesh in the two direction. We select any location from mesh and calculate total transportation time by using equations from Eqs. (1-10). Fig. 1 shows the radial, the tangent and the vertical movement respectively, being calculated from pervious equations. This procedure shall be done for all locations till it defines the minimum time needed, so it gets to the corresponding $X, Y$ of minimum time. The results of the implementation of the proposed method are shown in Figs. 3-6.
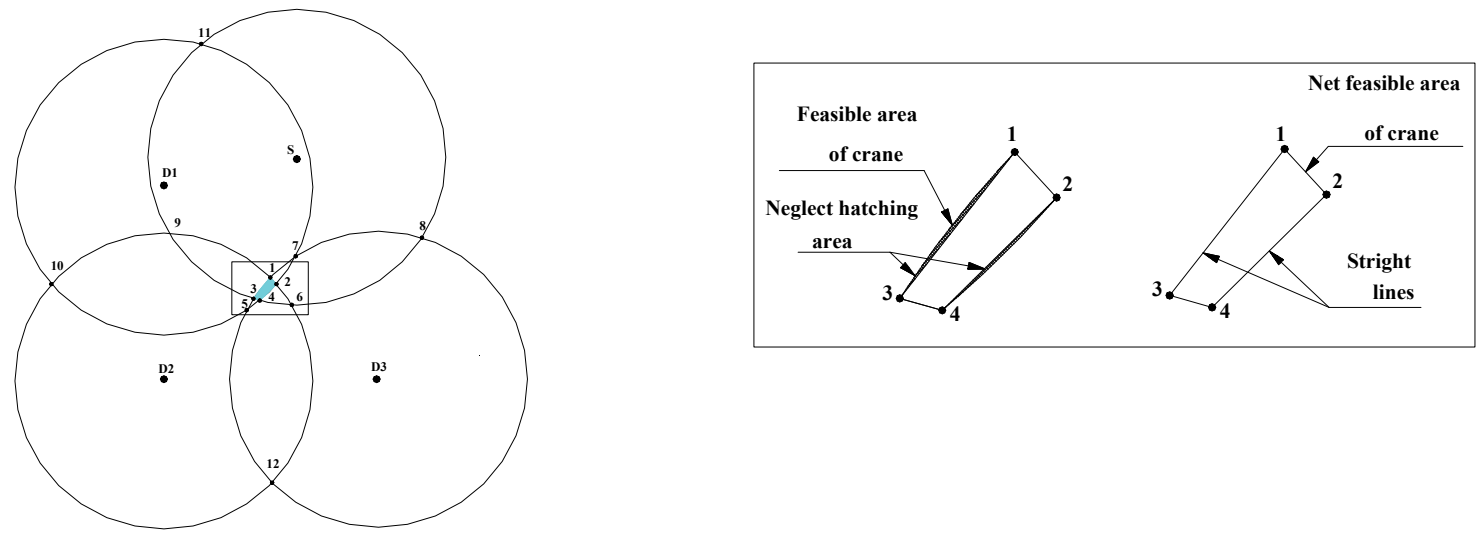

Fig. 3. Intersection locations and boundary of feasible area

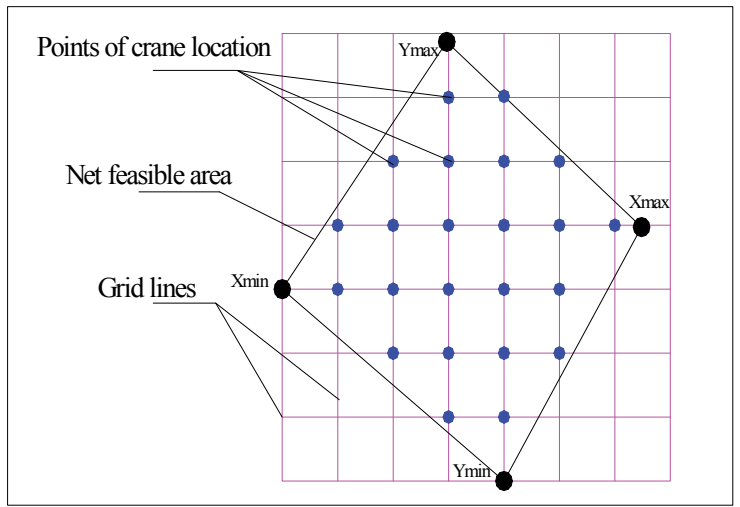

Fig. 4. Available crane locations.

\section{Illustrative example}

\subsection{Input data of illustrative example}

The main focus of this example is to illustrate the feature of the proposed model. The main material to be handled by tower crane is fresh concrete. Therefore, it is clear from the above discussion that location 
of tower crane is our essence of this research, assuming that all supply materials are (S). So coordinate location (S) and coordinates locations of demands $D 1, D 2, D 3$ are determined in the drawing of site layout. In addition, quantities needed for building to be handled by tower crane per stages shall be determined from each location of supply to demands locations. Fig. 5 shows the layout of site. Table 1 and Table 2 show the coordinates of demands and supply locations respectively, and Table 3 shows repeat lifting of material transported between every $S-D$ pair.

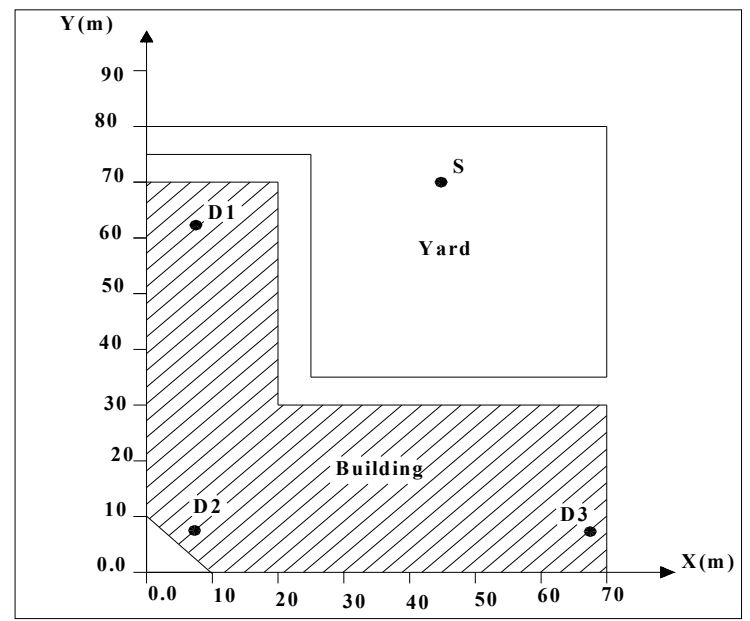

Fig. 5. Layout of site.

Table 1

Coordinate of demand locations

\begin{tabular}{llll}
\hline & $\mathrm{X}(\mathrm{m})$ & $\mathrm{Y}(\mathrm{m})$ & $\mathrm{Z}(\mathrm{m})$ \\
\hline D1 & 7.50 & 62.50 & 30.00 \\
D2 & 7.50 & 7.50 & 30.00 \\
D3 & 67.50 & 7.50 & 30.00 \\
\hline
\end{tabular}

Table 2

Coordinate of supply locations

\begin{tabular}{llll}
\hline Supply & D1 & D2 & D3 \\
\hline S & 45.00 & 70.00 & 0.0 \\
\hline
\end{tabular}

Table 3

Repeat lifting of material for pair S-D

\begin{tabular}{llll}
\hline Supply & D1 & D2 & D3 \\
\hline S & 1000 & 800 & 1200 \\
\hline
\end{tabular}

\section{Output data}

\subsection{Selection of minimum radius}

Based on the coordinate of supply and demand locations, the distant between each supply-demand can be determined. The largest distance of the obtained distance is selected $(81.40 \mathrm{~m})$. Finally, the minimum radius equal the half of this selected distance plus a selected margin (for example $0.50 \mathrm{~m}$, give a minimum intersection distance equal $1.0 \mathrm{~m}$ ). Table 4 shows calculation distance between all supply and demand locations, minimum radius using Eq. (12), which is equal to $42.00 \mathrm{~m}$. 


\subsection{Feasible area}

For this example, feasible area can be determined as follow:

The result of rounds of modeling with different radius, corresponding minimum time, coordinates location of crane, time of program and number gird inside the feasible area are shown in Table 6.

\section{Table 4}

Distance between supply and demand locations

\begin{tabular}{ll}
\hline Distance & Length $(\mathrm{m})$ \\
\hline & Eq. $(11)$ \\
\hline D1-S & 38.24 \\
D2-S & 72.89 \\
D3-S & 66.43 \\
D1-D2 & 55.00 \\
D1-D3 & 81.40 \\
D2-D3 & 60.00 \\
\hline
\end{tabular}

\section{Table 5}

Boundary locations the feasible area for $R=42 \mathrm{~m}$

\begin{tabular}{lll}
\hline Locations & $\mathrm{X}(\mathrm{m})$ & $\mathrm{Y}(\mathrm{m})$ \\
\hline 1 & 37.50 & 36.89 \\
2 & 39.25 & 35.00 \\
3 & 32.06 & 30.04 \\
4 & 33.58 & 29.58 \\
\hline
\end{tabular}

\section{Table 6}

Output data of illustrative example

Radius (m) Coordinates of tower crane

\begin{tabular}{ccccc}
\hline & $\mathrm{X}(\mathrm{m})$ & $\mathrm{Y}(\mathrm{m})$ & & \\
\hline 42 & 36.56 & 32.48 & 217.819 & 1657 \\
44 & 37.5 & 31.99 & 217.717 & 6789 \\
46 & 37.41 & 32.02 & 217.724 & 14415 \\
48 & 37.45 & 31.98 & 217.722 & 36341 \\
50 & 37.85 & 32.48 & 217.723 & 50562 \\
52 & 37.4 & 32.03 & 217.724 & 66671 \\
54 & 37.49 & 32.03 & 217.724 & 84695 \\
56 & 37.43 & 32.04 & 217.721 & 104579 \\
58 & 37.41 & 32.06 & 217.724 & 126284 \\
60 & 37.44 & 31.98 & 217.722 & 149780 \\
62 & 37.49 & 32.02 & 217.719 & 175039 \\
64 & 37.38 & 32.06 & 217.727 & \\
\hline
\end{tabular}

Fig. 6 shows the relationship between the minimum time and the radius. It is shown that increasing the radius from 42 to $64 \mathrm{~m}$ yields a change in time value from 217.727 to 217.819 hours. It can be selected 
from this figure the first minimum working radius value and corresponding time. The selected radiuses realize the optimum crane location.

\section{Conclusions}

The primary objective of this study performed on tower crane has been to reduce the cost through reducing time necessary for transportation operations or reducing capacity of winch or balancing between both. These changes may be according to conditions of site.

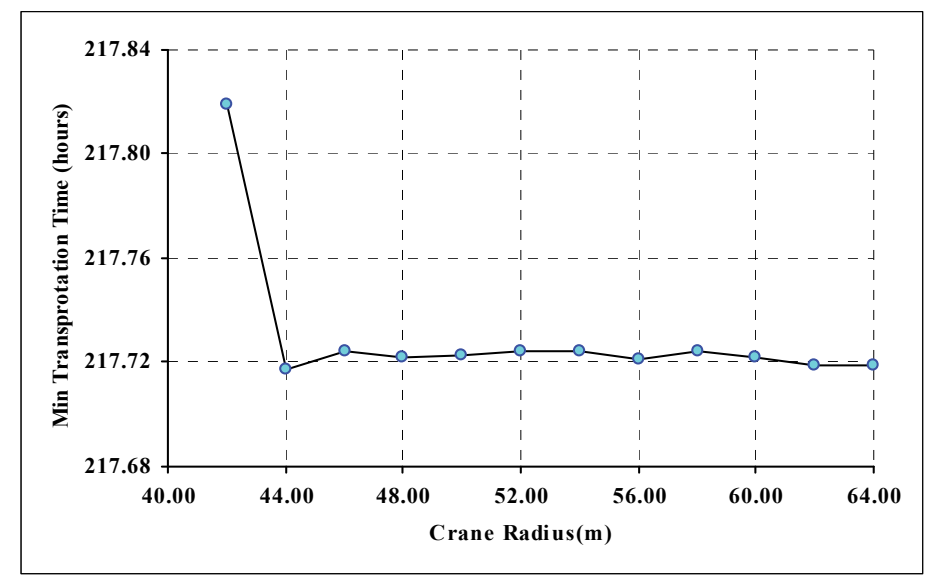

Fig. 6. Relation between transportation time and crane of radius

The study has attempted to locate the minimum radius and hence less capacity. Selection of tower crane according to selection of minimum time built on a definite radius and selection of minimum radius without considering transport time. The implementation of the proposed study has been accomplished using a computer program and the preliminary results have indicated that the method could be effectly used to reduce the cost and time.

\section{References}

Choi, C. W., \& Harris, F. C. (1991). Technical note. A model for determining optimum crane position. Proceedings of the Institution of Civil Engineers, 90(3), 627-634.

Farrell, C. W., \& Hover, K. C. (1989). Computerized crane selection and placement for the construction site. In 4. International Conference on Civil and Structural Engineering Computing. (Vol. 1, pp. 9194).

Furusaka, S., \& Gray, C. (1984). A model for the selection of the optimum crane for construction sites. Construction Management and Economics, 2(2), 157-176.

Gray, C., \& Little, J. (1985). A systematic approach to the selection of an appropriate crane for a construction site. Construction Management and Economics, 3(2), 121-144.

Herrera, I., \& Kaczmarczyk, S. (2016, May). Simple models for rope substructure mechanics: application to electro-mechanical lifts. In Journal of Physics: Conference Series (Vol. 721, No. 1, p. 012008). IOP Publishing.

Irizarry, J., \& Karan, E. P. (2012). Optimizing location of tower cranes on construction sites through GIS and BIM integration. Journal of Information Technology in Construction (ITcon), 17(23), 351366.

Olearczyk, J., Al-Hussein, M., \& Bouferguène, A. (2014). Evolution of the crane selection and on-site utilization process for modular construction multilifts. Automation in Construction, 43, 59-72.

Tam, C. M., Tong, T. K., \& Chan, W. K. (2001). Genetic algorithm for optimizing supply locations around tower crane. Journal of Construction Engineering and Management, 127(4), 315-321. 
Tubaileh, A. (2016). Working time optimal planning of construction site served by a single tower crane. Journal of Mechanical Science and Technology, 30(6), 2793-2804.

Warszawski, A. (1973). Analysis of transportation methods in construction. Journal of the Construction Division, 99(1), 191-202.

Wijesundera, D. A., \& Harris, F. C. (1986). Computer simulation for materials handling in high rise construction. In Proceedings of the International AMSE Conference on Modeling and Simulation, Sorrento, Italy (Vol. 4, pp. 81-95).

Wu, D., Lin, Y., Wang, X., Wang, X., \& Gao, S. (2010). Algorithm of crane selection for heavy lifts. Journal of Computing in Civil Engineering, 25(1), 57-65.

Xiaoyi, Y., Baoshan, L., \& Mingxiang, P. (2009). Selection and location of tower crane used in CCTV main building. Construction Technology, 4, 015.

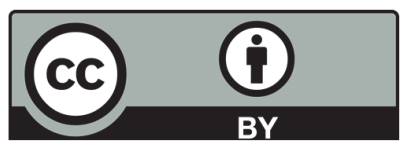

(C) 2017 by the authors; licensee Growing Science, Canada. This is an open access article distributed under the terms and conditions of the Creative Commons Attribution (CC-BY) license 